\title{
Scaling in stream communities
}

\author{
Peter E. Schmid ${ }^{1 *}$, Mutsunori Tokeshi ${ }^{2}$ and Jenny M. Schmid-Araya ${ }^{1}$ \\ ${ }^{1}$ School of Biological Sciences, Queen Mary, University of London, London E1 4NS, UK \\ ${ }^{2}$ Amakusa Marine Biological Laboratory, Kyushu University, Tomioka, Reihoku-Amakusa, Kumamoto, fapan
}

\begin{abstract}
Scaling relationships between population density $(N)$ and body size $(W)$, and of their underlying size distributions, can contribute to an understanding of how species use resources as a function of size. In an attempt to resolve the controversy over the form of scaling relationships, an extensive dataset, comprising 602 invertebrate species, was obtained from two geographically separate stream communities (Seebach in Austria and Mynach in Wales). We analysed the temporal consistency of the $N-W$ relationship, which was subjected to ordinary least squares (OLS), bisector $\left(\mathrm{OLS}_{\mathrm{BIS}}\right)$ and quantile regressions, and speciessize spectra with seasonally collated data. Slopes of seasonal $\mathrm{OLS}_{\mathrm{BIS}}$ regressions did not depart from -1 in either community, indicating a seasonally convergent scaling relationship, which is not energetically constrained. Species-size spectra may scale with habitat complexity, providing an alternative explanation for the observed body-size scaling. In contrast to the right-skewed species-size frequency distributions of single-species assemblages, the size spectra of these benthic communities exhibited 'central tendencies', reflecting their phyletic constitution. The shape of species body-mass spectra differed between the two communities, with a bimodal and seasonally convergent pattern in the Seebach community and a seasonally shifting unimodality in the Mynach community. The body-size spectra of large, mostly insect, species (greater than or equal to $1 \mathrm{~mm}$ ) scaled to seasonal variations in habitat complexity (i.e. fractal $D$ ), suggesting that habitat structure constrains the community organization of stream benthos.
\end{abstract}

Keywords: scaling; body-size spectra; communities; fractal dimension; habitat complexity; streams

\section{INTRODUCTION}

Macroecological approaches emphasize the existence of community patterns, which reflect the operation of general principles or natural laws (Brown 1995; Marquet 2000). Despite the complexity of ecosystems, empirical scaling phenomena appear to dictate how biological features change with size (West et al. 1999). Body size has received much attention in the ecological and evolutionary literature because many life-history traits are correlated with it (Harvey \& Pagel 1991). Allometric rules that scale biological processes according to size in organisms have long been recognized and are used to predict the dynamics of complex assemblages in nature (Peters 1983; Damuth 1987; Cyr 2000).

The distribution of body size among species within a geographical area may yield insights into the evolutionary and ecological processes structuring species assemblages. In nature, small organisms are found at higher densities than are large organisms. Across a range of aquatic and terrestrial habitats, the inverse scaling 'law' describing the relationship between mean population density $(N)$ and body mass ( $W$ ) has yielded ordinary least squares (OLS) slopes close to -0.75 (Marquet et al. 1990; Schmid et al. 2000). Since individual basal metabolic rates $(R)$ scale with body mass according to $R \propto W^{0.75}$ (Peters 1983), the value of exponent between size and abundance $(-0.75)$ has been interpreted as indicating an energetic limitation of population abundance. However, variation in the regression slopes among different taxa and inconsistency of trends when using different regression models strongly

*Author for correspondence (p.e.schmid@qmul.ac.uk). suggest that these communities are not governed by a single energetic rule (Schmid et al. 2000). Further, even where $b=-3 / 4$ appears to fit, the reasons, biological or otherwise, remain elusive and open to question.

More importantly, metabolic explanations often ignore the frequency distribution of species' body size, which underlies $N-W$ relationships. These species-size spectra may display patterns independent of metabolic constraints, and could lead to other scale-related explanations. Body-size spectra of single-species assemblages frequently display modal patterns, such that there are many more species of intermediate than of large or small size (Brown 1995). May (1986) suggested that the number of species $(S)$ of a given size decreases as their characteristic linear dimension $(L)$ increases, such that $S \propto L^{-2}$ or $W^{-2 / 3}$, because smaller modal-sized species subdivide their environment more finely. This argument essentially implies that the habitat may be used by animals in two dimensions, and a possible increase in species number scales as $L^{-2}$. Recent studies have shown that the fractal dimension of habitat structure, such as of plants and soil, affects the distribution of organisms of different sizes (Morse et al. 1985; Lawton 1986; Kampichler 1999). In lotic benthic ecosystems, the spatial distribution of organisms may also be linked to habitat complexity and fractal properties that, in turn, are influenced by geology, grainsize composition and flow. It can be assumed that, in heterogeneous sediments, larger, mostly insect, species, which are mainly surface dwellers, use the habitat along a one- to two-dimensional continuum, which scales with a fractal dimension $D \geqslant 1$. In the interstitial environment, where most smaller species occur, resource use may also remain in a one- to two-dimensional continuum, as many of these species occupy the surfaces of small particles. A 
Table 1. Regression slopes for the relationship between mean body size ( $\mu$ g dry mass) and population density (individuals $\mathrm{m}^{-2}$ ) in benthic invertebrate communities for each season in the Oberer Seebach (SB) and Afon Mynach (MY).

( $n$, number of species; $r^{2}$, proportion of variance explained by the correlation of body size with densities of all species; $G_{\mathrm{LAD}}$, coefficient of determination for least absolute deviation (LAD) regression; $b_{\mathrm{OLS}}$, slope of the ordinary least-squares regression [OLS $(y \mid x)] ; b_{\mathrm{BIS}}$, slope of the ordinary least-squares bisector regression $\left(\mathrm{OLS}_{\mathrm{BIS}}\right) ; b_{\mathrm{LAD}}$, slope of the LAD regression, calculated across all species found in the community at each season. Bias-adjusted bootstrap confidence limits (95\%) based on 5000 bootstrap replications are given in parentheses for all $b$ values.)

\begin{tabular}{|c|c|c|c|c|c|c|}
\hline & $n$ & $r^{2}$ & $b_{\mathrm{OLS}}$ & $b_{\mathrm{BIS}}$ & $G_{\mathrm{LAD}}$ & $b_{\mathrm{LAD}}$ \\
\hline \multicolumn{7}{|l|}{ SB } \\
\hline autumn & 385 & 0.404 & $\begin{array}{c}-0.594^{\mathrm{a}-\mathrm{c}} \\
(-0.662,-0.525)\end{array}$ & $\begin{array}{c}-0.940^{\mathrm{a}-\mathrm{c}} \\
(-0.997,-0.883)\end{array}$ & 0.221 & $\begin{array}{c}-0.609^{\mathrm{a}, \mathrm{c}} \\
(-0.725,-0.493)\end{array}$ \\
\hline winter & 375 & 0.434 & $\begin{array}{c}-0.645^{\mathrm{a}, \mathrm{c}} \\
(-0.716,-0.572)\end{array}$ & $\begin{array}{c}-0.980^{\mathrm{a}, \mathrm{b}} \\
(-1.037,-0.921)\end{array}$ & 0.225 & $\begin{array}{c}-0.665^{\mathrm{c}} \\
(-0.770,-0.561)\end{array}$ \\
\hline spring & 397 & 0.382 & $\begin{array}{c}-0.621^{\mathrm{a}, \mathrm{c}} \\
(-0.698,-0.543)\end{array}$ & $\begin{array}{c}-1.006^{\mathrm{a}, \mathrm{b}} \\
(-1.064,-0.947)\end{array}$ & 0.195 & $\begin{array}{c}-0.623^{c} \\
(-0.776,-0.471)\end{array}$ \\
\hline summer & 389 & 0.359 & $\begin{array}{c}-0.612^{\mathrm{a}, \mathrm{c}} \\
(-0.687,-0.536)\end{array}$ & $\begin{array}{c}-1.018^{\mathrm{a}, \mathrm{b}} \\
(-1.079,-0.958)\end{array}$ & 0.183 & $\begin{array}{c}-0.582^{\mathrm{a}, \mathrm{c}} \\
(-0.701,-0.463)\end{array}$ \\
\hline \multicolumn{7}{|c|}{ ( } \\
\hline autumn & 249 & 0.456 & $\begin{array}{c}-0.745^{\mathrm{c}} \\
(-0.837,-0.653)\end{array}$ & $\begin{array}{c}-1.095^{\mathrm{a}-\mathrm{c}} \\
(-1.179,-1.012)\end{array}$ & 0.288 & $\begin{array}{c}-0.800^{\mathrm{c}} \\
(-0.913,-0.688)\end{array}$ \\
\hline winter & 187 & 0.440 & $\begin{array}{c}-0.669^{c} \\
(-0.769,-0.565)\end{array}$ & $\begin{array}{c}-1.008^{\mathrm{a}, \mathrm{b}} \\
(-1.103,-0.914)\end{array}$ & 0.264 & $\begin{array}{c}-0.656^{\mathrm{c}} \\
(-0.780,-0.531)\end{array}$ \\
\hline spring & 243 & 0.305 & $\begin{array}{c}-0.557^{\mathrm{a}-\mathrm{c}} \\
(-0.646,-0.467)\end{array}$ & $\begin{array}{c}-1.007^{\mathrm{a}, \mathrm{b}} \\
(-1.084,-0.931)\end{array}$ & 0.178 & $\begin{array}{c}-0.626^{\mathrm{c}} \\
(-0.763,-0.488)\end{array}$ \\
\hline summer & 227 & 0.413 & $\begin{array}{c}-0.656^{\mathrm{a}, \mathrm{c}} \\
(-0.744,-0.570)\end{array}$ & $\begin{array}{c}-1.020^{\mathrm{a}, \mathrm{b}} \\
(-1.102,-0.940)\end{array}$ & 0.277 & $\begin{array}{c}-0.694^{\mathrm{c}} \\
(-0.780,-0.608)\end{array}$ \\
\hline
\end{tabular}

a OLS, LAD and $\mathrm{OLS}_{\mathrm{BIS}} b$ values significantly departing from $-0.75,-0.77$ and -0.8 , respectively.

${ }^{\mathrm{b}} \mathrm{OLS}, \mathrm{LAD}$ and $\mathrm{OLS}_{\mathrm{BIS}} b$ values significantly departing from $-0.67,-0.68$ and -0.7 , respectively.

${ }^{c} b$ values significantly departing from -1 (Monte Carlo simulation tests, $p<0.05$ ).

stream bed with small voids is more likely to be occupied by small taxa, given the fractal nature of the particle-pore boundary in benthic habitats (Schmid 2000). This suggests that possible variation in the scaling exponent of species-size spectra relates to variation in habitat complexity (i.e. fractal dimension).

We used empirical data on population density and body weight, and species-size spectra derived from invertebrate communities in two geographically separated gravel streams. We examined the temporal consistency of the species size and density distributions on a seasonal timescale, with reference to the three hypothetical scaling values $b=-2 / 3, b=-3 / 4$ and $b=-1$, and considered the proposition that variation in habitat structure translates to the scaling of seasonally variable species-size spectra.

\section{MATERIAL AND METHODS}

\section{(a) Sampling and processing}

Two gravel streams, the Afon Mynach (MY), a tributary of the River Dee in North Wales $\left(52^{\circ} 57^{\prime} \mathrm{N}, 3^{\circ} 38^{\prime} \mathrm{W}\right.$; $260 \mathrm{~m}$ above sea level), and the Oberer Seebach (SB), in Lower Austria $\left(47^{\circ} 51^{\prime} \mathrm{N}, 5^{\circ} 04^{\prime} \mathrm{E}\right.$; $615 \mathrm{~m}$ above sea level), were chosen for study. The stream bed in the MY is composed mainly of mudstone, while dolomite limestone comprises the stream bed of the SB. Both streams are circumneutral ( $\mathrm{pH} c a .7$ ), with mean annual discharges of 0.86 (s.e. $=0.06) \mathrm{m}^{3} \mathrm{~s}^{-1}$ in $\mathrm{SB}$ and 1.02 (s.e. $=0.12) \mathrm{m}^{3} \mathrm{~s}^{-1}$ in $\mathrm{MY}$ during the sampling period (SB: 1991-1994; MY: 1993-1997). In each stream, extensive quantitative sampling of organisms was conducted at variable intervals (mainly monthly or bimonthly) in three riffle and two pool areas within a $100 \mathrm{~m}$ stretch using modified Hess samplers (mesh-size of $50 \mu \mathrm{m}$ ) to a sediment depth of $10 \mathrm{~cm}$, using three different sampler sizes $\left(100,200\right.$ and $\left.300 \mathrm{~cm}^{2}\right)$. Losses of small organisms and particles (smaller than $50 \mu \mathrm{m}$ ) were negligible, because the $50 \mu \mathrm{m}$ mesh net clogged rapidly (Schmid-Araya 1994). A total of 281 and 286 Hess samples were collected from the SB and the MY, respectively. In addition, in each stream 30 freeze-cores with prior electropositioning (sensu Bretschko \& Klemens 1986) were obtained from sediment layers down to $40 \mathrm{~cm}$, bimonthly between November 1993 and November 1994 (see electronic Appendix A available on The Royal Society's Publications Web site). As $80 \%-97 \%$ of all invertebrates occurred within the first $10 \mathrm{~cm}$ of sediment (Schmid 1993) and different samples (freezecore and Hess) needed to be standardized, only samples collected from the top layer were used for analysis.

All invertebrates were identified and counted under variable magnifications $(\times 25-250)$ (see Schmid et al. (2000) for a list of taxa). The abundances of smaller organisms were assessed by splitting each sample into ten $1 \mathrm{ml}$ subsamples. Body length, width and height of at least 300 individuals of each species were measured to the nearest $5 \mu \mathrm{m}$ using an eyepiece micrometer and an image-analysis system. Body mass (dry weight) of species that vary greatly in size between larval stages (insects) was obtained from length-weight regressions (details in Schmid et al. 2000).

\section{(b) Fractal habitat structure and species-size spectra}

The particle-void interface of vertical and horizontal crosssections of stream-bed habitat (resolution of $\geqslant 1 \mathrm{~mm}$ ) was analysed by the Minkowski technique (Schmid 2000), using photographs of $80(\mathrm{SB})$ and $64(\mathrm{MY})$ freeze-core samples. The Minkowski dimension was determined from images taken under six different magnifications, by placing small circles (pixels) of 
(a)

(i)

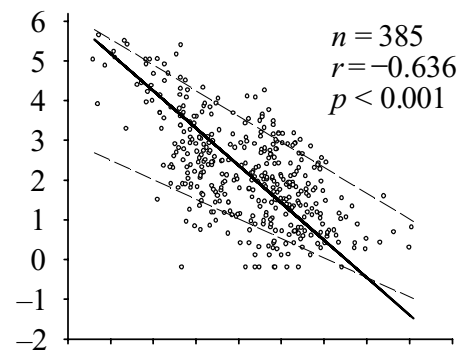

(ii)

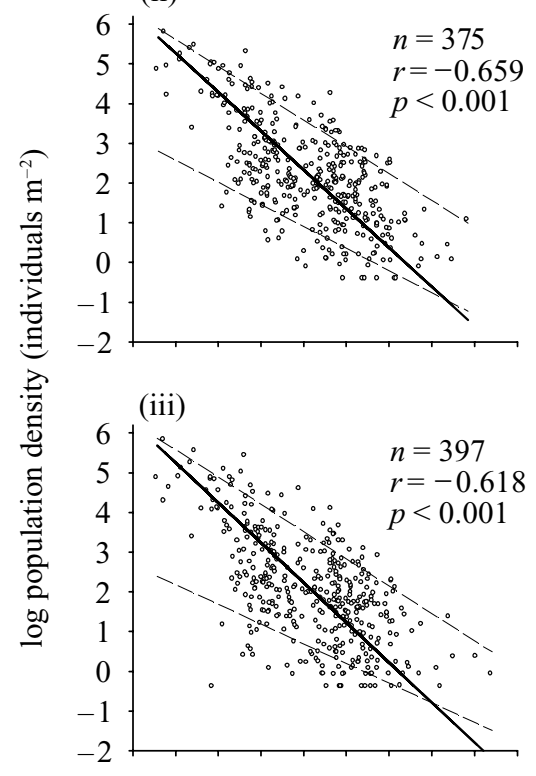

(iv)

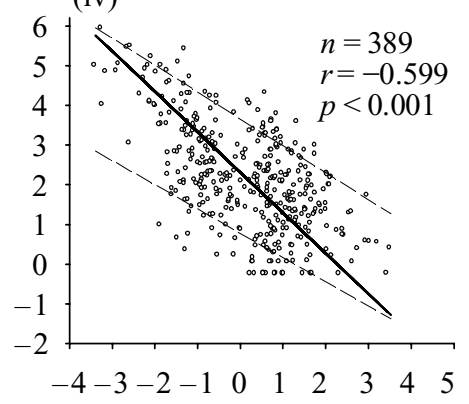

(b)

(i)

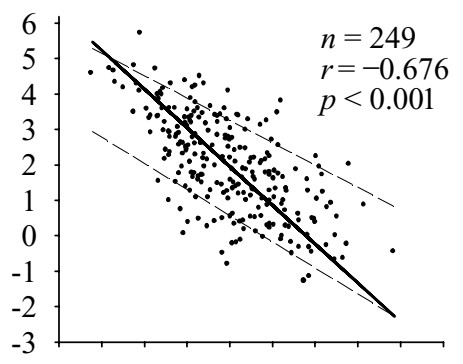

(ii)

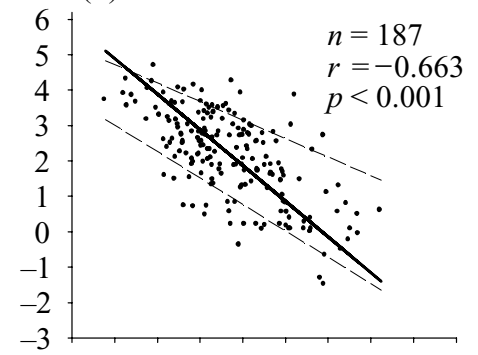

(iii)

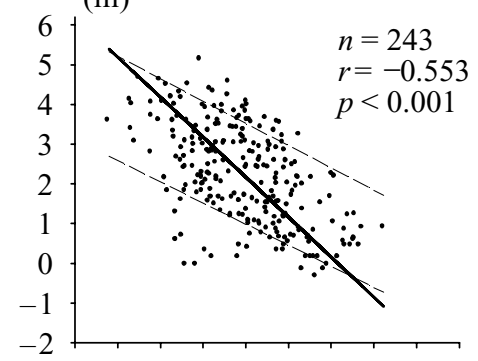

(iv)

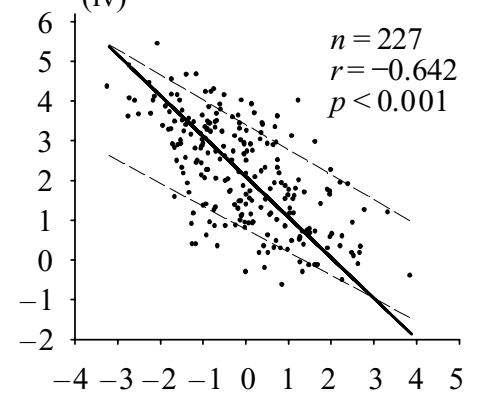

$\log$ body mass ( $\mu \mathrm{g}$ dry mass)

Figure 1. Linear regressions of $\log _{10}$ population density on $\log _{10}$ body mass of benthic invertebrate species found at each

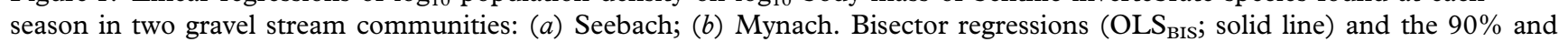
$10 \%$ quantile regressions (dashed lines) are fitted over all species in each season and stream; (i) autumn, (ii) winter, (iii) spring and (iv) summer. All regressions were statistically significant $(p<0.05)$. Regression exponents are given in tables 1 and $2 ; n$ is the number of species; $(a(\mathrm{i})) b_{\mathrm{BIS}}=-0.940 ;(a(\mathrm{ii})) b_{\mathrm{BIS}}=-0.980 ;(a(\mathrm{iii})) b_{\mathrm{BIS}}=-1.006 ;(a$ (iv) $) b_{\mathrm{BIS}}=-1.018$; $(b(\mathrm{i})) b_{\mathrm{BIS}}=-1.095 ;(b(\mathrm{ii})) b_{\mathrm{BIS}}=-1.008 ;(b(\mathrm{iii})) b_{\mathrm{BIS}}=-1.007 ;(b(\mathrm{iv})) b_{\mathrm{BIS}}=-1.020$.

radius $\lambda$ centred on all points of the particle-void interface. The resulting linked circles form a 'ribbon' overlying the boundary, and the sum of their areas is denoted by $A(\lambda)$. This value is divided by $2 \lambda$, and the process repeated for logarithmically increasing pixels of radius $\lambda$. The Minkowski dimension $\left(D_{\mathrm{M}}\right)$ is defined by the equation $A(\lambda) / 2 \lambda \propto \lambda^{1-D_{\mathrm{M}}}$, and derived using those scales of the particle-void boundary that exhibit statistical self-similarity. $D_{M}$ values theoretically range between 1 and 2, with larger values corresponding to more heterogeneous interfaces.

Assuming that invertebrates use the habitat in one to two dimensions, proportional to their body length, fractal theory can be applied to characterize the size distribution of species. Specifically, the fractal relationship for aggregate size distributions (sensu Mandelbrot 1983) is defined by $S(\Lambda>\lambda) \propto \lambda^{-D}$, where $S(\Lambda>\lambda)$ is the cumulative number of species $(S)$ of body length $\Lambda$ larger than a specific measuring scale $\lambda$, as determined by the size intervals, and $D$ is the fractal dimension. In a similar manner to $D_{\mathrm{M}}, D$ is a measure of the boundary dimension, and the values of $D$ and $D_{\mathrm{M}}$ depend on the size-frequency fragmentation across all scales considered. Therefore, if species-size spectra scale with habitat complexity, the fractal scaling of the species-size relation would manifest as $D \approx D_{M}$. Given this 
Table 2. Simultaneous-quantile regression slopes for the relationship between population density and body size in the SB and $M Y$ in each season.

(b, slope of $1 \%, 10 \%, 90 \%$ and $99 \%$ quantile regressions; $p_{\mathrm{Q} 50}$, probability of slope departing from the LAD (median) regression. Bootstrap confidence limits (95\%) based on 5000 bootstrap replications are given in parentheses for all $b$ values.)

\begin{tabular}{|c|c|c|c|c|c|c|c|c|}
\hline \multirow[b]{2}{*}{ quantile } & \multicolumn{2}{|l|}{ autumn } & \multicolumn{2}{|l|}{ winter } & \multicolumn{2}{|l|}{ spring } & \multicolumn{2}{|c|}{ summer } \\
\hline & $b$ & $p_{\mathrm{Q} 50}$ & $b$ & $p_{\mathrm{Q} 50}$ & $b$ & $p_{\mathrm{Q} 50}$ & $b$ & $p_{\mathrm{Q} 50}$ \\
\hline \multicolumn{9}{|l|}{ SB } \\
\hline 0.01 & $\begin{array}{c}0.000^{\mathrm{a}} \\
(-0.573,0.573)\end{array}$ & 0.035 & $\begin{array}{c}-0.433 \\
(-0.623 \\
-0.244)\end{array}$ & 0.034 & $\begin{array}{c}0.000^{\mathrm{a}} \\
(-0.304,0.304)\end{array}$ & $<0.001$ & $\begin{array}{c}-0.321 \\
(-0.508 \\
-0.135)\end{array}$ & 0.018 \\
\hline 0.10 & $\begin{array}{c}-0.492 \\
(-0.675,-0.310)\end{array}$ & 0.205 & $\begin{array}{c}-0.555 \\
(-0.723 \\
-0.387)\end{array}$ & 0.212 & $\begin{array}{c}-0.495 \\
(-0.707 \\
-0.283)\end{array}$ & 0.248 & $\begin{array}{c}-0.610 \\
(-0.781 \\
-0.439)\end{array}$ & 0.761 \\
\hline 0.90 & $\begin{array}{c}-0.646 \\
(-0.713,-0.579)\end{array}$ & 0.527 & $\begin{array}{c}-0.674 \\
(-0.743 \\
-0.605)\end{array}$ & 0.879 & $\begin{array}{c}-0.687 \\
(-0.771 \\
-0.603)\end{array}$ & 0.387 & $\begin{array}{c}-0.677 \\
(-0.741 \\
-0.614)\end{array}$ & 0.105 \\
\hline 0.99 & $\begin{array}{c}-0.801 \\
(-1.019,-0.584)\end{array}$ & 0.121 & $\begin{array}{c}-0.742 \\
(-0.959 \\
-0.524)\end{array}$ & 0.536 & $\begin{array}{c}-0.806 \\
(-1.046 \\
-0.567)\end{array}$ & 0.197 & $\begin{array}{c}-0.562 \\
(-0.791 \\
-0.333)\end{array}$ & 0.879 \\
\hline \multicolumn{9}{|l|}{ MY } \\
\hline 0.01 & $\begin{array}{c}-0.477 \\
(-0.838,-0.116)\end{array}$ & 0.078 & $\begin{array}{l}-0.677 \\
(-1.006 \\
-0.349)\end{array}$ & 0.899 & $\begin{array}{c}-0.050^{\mathrm{a}} \\
(-0.329,0.134)\end{array}$ & $<0.001$ & $\begin{array}{l}-0.483 \\
(-0.791 \\
-0.175)\end{array}$ & 0.190 \\
\hline 0.10 & $\begin{array}{c}-0.738 \\
(-1.034,-0.442)\end{array}$ & 0.664 & $\begin{array}{c}-0.747 \\
(-1.063 \\
-0.431)\end{array}$ & 0.558 & $\begin{array}{c}-0.532 \\
(-0.738 \\
-0.326)\end{array}$ & 0.388 & $\begin{array}{c}-0.578 \\
(-0.771 \\
-0.385)\end{array}$ & 0.240 \\
\hline 0.90 & $\begin{array}{c}-0.631 \\
(-0.807,-0.455)\end{array}$ & 0.069 & $\begin{array}{c}-0.523 \\
(-0.746 \\
-0.301)\end{array}$ & 0.228 & $\begin{array}{c}-0.561 \\
(-0.747 \\
-0.375)\end{array}$ & 0.546 & $\begin{array}{c}-0.628 \\
(-0.810 \\
-0.446)\end{array}$ & 0.469 \\
\hline 0.99 & $\begin{array}{c}-0.698 \\
(-1.036,-0.360)\end{array}$ & 0.567 & $\begin{array}{c}-0.252^{\mathrm{a}} \\
(-0.600,0.096)\end{array}$ & 0.026 & $\begin{array}{r}-0.807 \\
(-1.085 \\
-0.529)\end{array}$ & 0.245 & $\begin{array}{c}-0.652 \\
(-0.957 \\
-0.347)\end{array}$ & 0.789 \\
\hline
\end{tabular}

${ }^{a} b$ values not significantly departing from $0(p<0.05)$.

assumption and a lower resolution threshold $(c a .1 \mathrm{~mm})$ of the particle-pore boundary, possible body-size scaling is expected to hold at least for species greater than or equal to this threshold.

\section{(c) Statistical analyses}

The data used in the present study refer to values calculated for a standardized surface area $\left(1 \mathrm{~m}^{2}\right)$ over all samples collected in a particular season. To compare our data with published results we used OLS $(y \mid x)$ regressions. In addition, least absolute deviation regressions (LAD) were performed to reduce the effect of outliers and to increase the resistance to heavy-tailed error distributions in the datasets (Draper \& Smith 1998). LAD regression minimizes the sum of the absolute deviations and estimates the conditional median ( 0.5 regression quantile) of $y$ given $x$, while its generalization, the regression quantiles, estimates the conditional quantile, $\tau$ (where $0<\gamma<1$ ) of $y$ given $x$. These quantile regressions can be used to quantify the upper and lower boundaries of population density and to examine variation in density with body size (Scharf et al. 1998). Thus, simultaneous quantile regressions were performed with 5000 bootstrap replications of the entire variance-covariance matrix. To test whether the boundary regressions differed from the LAD (median) regressions in terms of slope values, we chose the upper boundary as the 99th and 90th quantiles and the lower boundary as the 1 st and 10th quantiles of the $N-W$ relationship.

For data with an unclear distinction of dependent and independent variables, a method treating $x$ and $y$-values symmetrically may be more appropriate. For this reason, the bisector regression $\left(\mathrm{OLS}_{\mathrm{BIS}}\right)$, i.e. the line that bisects the angle formed by the $\operatorname{OLS}(y \mid x)$ and the inverse $\operatorname{OLS}(x \mid y)$, was also used in the present study. It has a smaller variance about its theoretical fit than other LS regressions, and is superior to the reduced major axis regression method (Isobe et al. 1990). A detailed account of the formal mathematical and statistical properties of the $\mathrm{OLS}_{\mathrm{BIS}}$ regression is given in Babu \& Feigelson (1992).

Density-body-size relationships were compared among seasons by ANCOVA. From Peters' (1983; Appendix IIIb) OLS regression parameters on $R-W$ relationships of aquatic invertebrate taxa, slopes were derived for OLS $_{\mathrm{BIS}}$ and LAD as 0.8 and 0.77 , respectively (corresponding to $b=3 / 4$ ), and as 0.7 and 0.68 , respectively (for $b=2 / 3$ ).

To examine and compare seasonal body-size spectra, Gaussian kernel estimations and iterated searches for critical bandwidths (smoothing constant) were conducted (sensu Efron \& Tibshirani 1993) on $\log _{10}$-transformed data. This method of analysing multimodality permits the estimation of (i) the location of modes and troughs and (ii) the likely number of modes in the distribution. We used an unbalanced two-way ANOVA to test for differences in mean body size between the streams and across seasons. Statistical analyses and simulations were programmed with Borland Delphi 5 implemented with EcoStatistics software (P. E. Schmid, unpublished data) and Stata 6.0 (StataCorp 1999). 


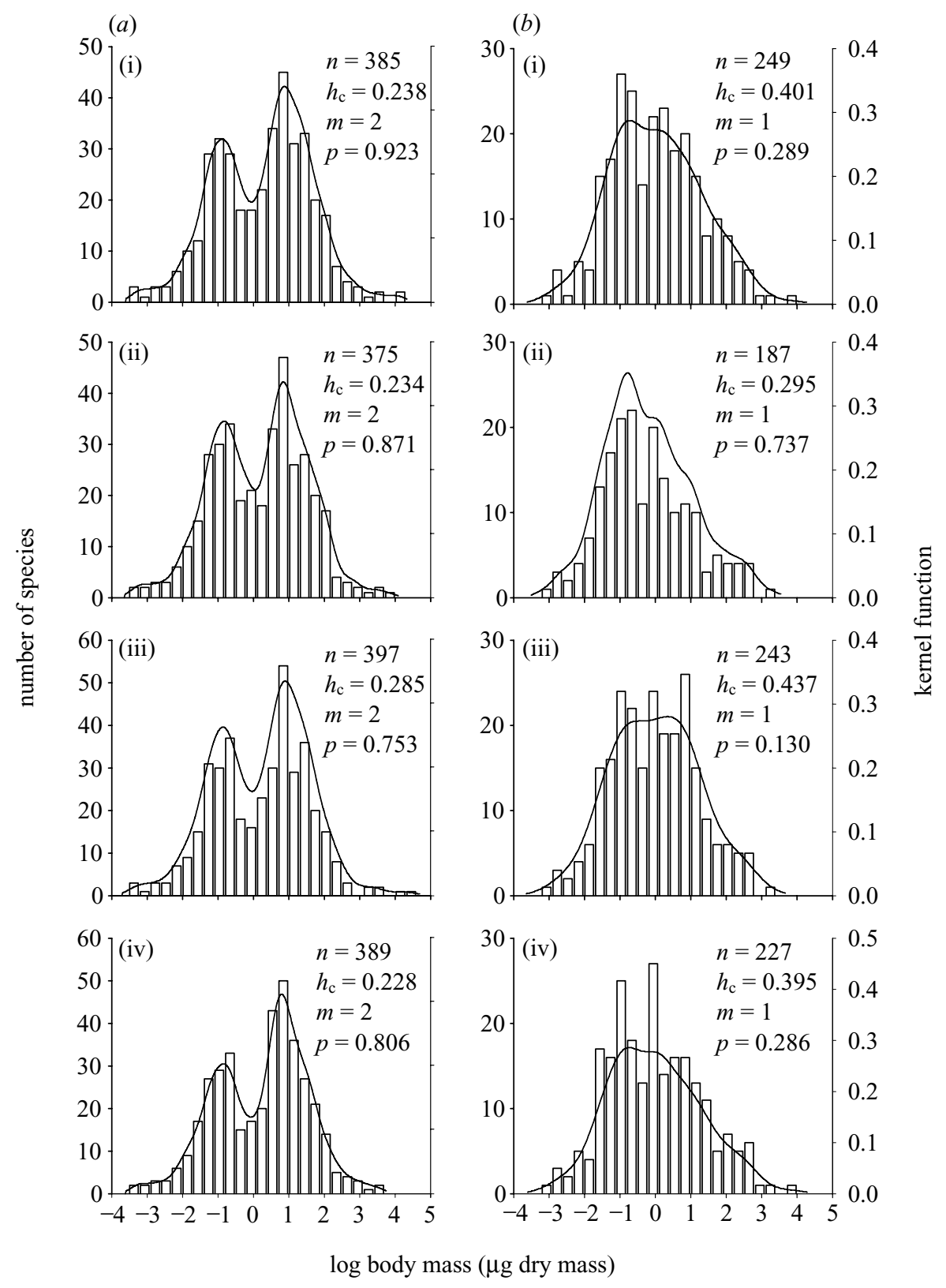

Figure 2. Species body-mass spectra (bars) and fitted distributions estimated by the kernel function and smoothed bootstrapped re-sampling (solid line) for each season in (a) Seebach and (b) Mynach; $n$ is the number of species, $h_{\mathrm{c}}$ is the critical bandwidth used in the kernel function, $m$ is the smallest number of modes for which the bootstrap test was not significant at the $5 \%$ level and $p$ is the level of significance for each mode number. Seasons: (i) autumn, (ii) winter, (iii) spring and (iv) summer.

\section{RESULTS}

\section{(a) Population-density and body-size scaling}

In both stream communities, seasonal mean density declined in a broad band with increasing body mass without evidence of a peaked pattern (figure 1). The OLS slopes did not differ between seasons in the SB (ANCOVA: $F_{3,1538}=0.29, p=0.831$ ) or in the MY (ANCOVA: $F_{3,898}=2.20, p=0.086$ ). For the OLS regression, departures from $b=-3 / 4$ occurred in all seasons in the SB and in spring and summer in the MY (table 1). The value $b=-2 / 3$ had to be rejected for autumn and spring data from the SB and MY, respectively, while the OLS slopes differed significantly from -1 in all seasons in both streams (table 1).
By contrast, the $\mathrm{OLS}_{\mathrm{BIS}}$ slopes were close to -1 ; these and the LAD slopes were also similar between seasons (table 1). Contrary to the least-squares analysis, none of the LAD slopes rejected $b=-2 / 3$, while $b=-3 / 4$ had to be rejected for SB data from the autumn and summer (table 1).

\section{(b) Upper and lower boundary relations}

Because densities fluctuated over several orders of magnitude in the two streams, $N-W$ relationships may be biased towards maximum and minimum densities. Upper and lower boundary slopes of quantile regressions (figure 1 ; based on the 10th and 90th quantiles) were not significantly different from the median (LAD) regression slope (table 2). The upper boundary slopes of the 99th quantile 
$(a)$
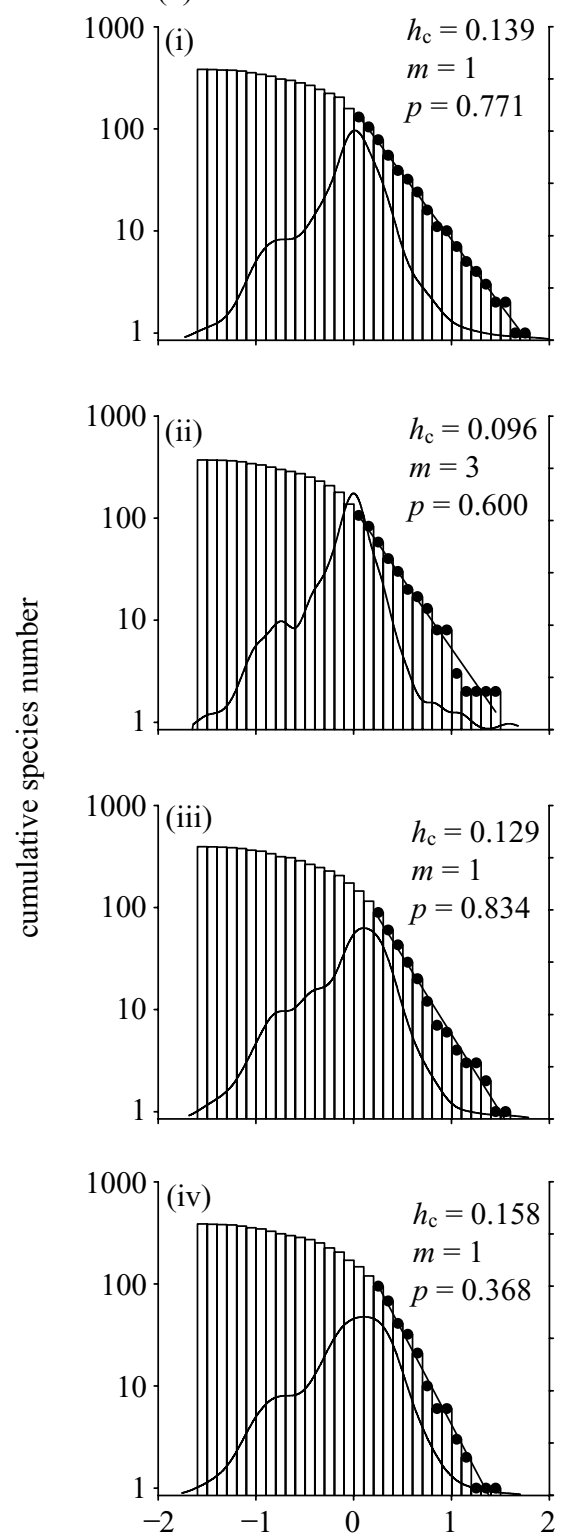

(b)
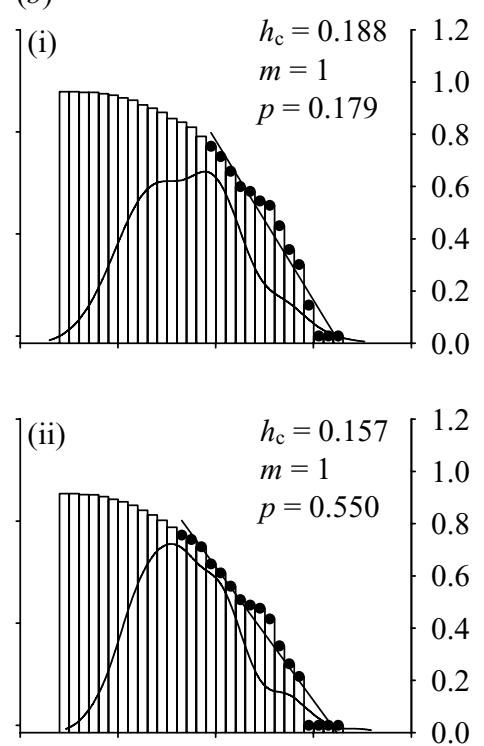

(iii)
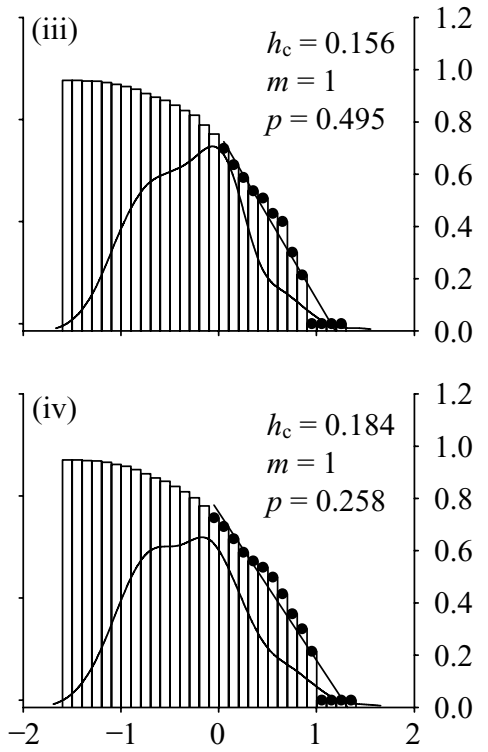

$\log$ body length $(\mathrm{mm})$

Figure 3. Cumulative species body-length spectra (bars) and fitted distributions estimated by the kernel function and smoothed bootstrapped re-sampling (solid line) for each season in (a) Seebach and (b) Mynach; $h_{\mathrm{c}}$ is the critical bandwidth, $m$ is the number of significant modes and $p$ is the level of significance for each distribution. Seasons: (i) autumn, (ii) winter, (iii) spring and (iv) summer. Linear regressions (OLS) of $\log _{10}$ species number on $\log _{10}$ body length of all species to the right of the mode at each season in two gravel stream communities. All regressions were statistically significant $(p<0.05)$. Regression exponents are given in table 3.

showed a similar tendency, except in the winter MY data, where the slope did not depart significantly from 0 (table 2). Moreover, lower boundary slopes based on the 1 st quantile did not depart significantly from 0 in spring in the SB and MY and in autumn in the SB data (table 2). The close fit of upper boundary slopes to the median regression slopes confirms the general prediction of the LAD slopes for maximum population densities in both communities.

\section{(c) Species body-size frequency distribution}

The body size of all species differed significantly between streams (two-way ANOVA: $F_{1,2444}=29.39$, $p$
$<0.001$ ), with larger sizes in the SB than in the MY, but there was neither a significant difference between seasons $\left(F_{3,2444}=1.58, p=0.192\right)$ nor an interaction between seasons and streams $\left(F_{3,2444}=0.53, p=0.661\right)$. Species-size spectra showed a consistent pattern in the most likely number of modes through seasons (figure 2). Two significant modes (figure $2 ; p<0.05$ ), a smaller one corresponding to meiofauna and a larger one corresponding to small insect larvae, occurred in the SB, while only one significant mode occurred in the MY. By contrast, the MY community was characterized by a shift in species-size frequency peaks, from autumn (meiofaunal species) to summer (small insects) (figure 2). 
Table 3. Mean Minkowski dimension $\left(D_{M}\right)$ of particle-void boundaries in horizontal and vertical sediment cross-sections, and regression exponents $\left(b_{\mathrm{OLS}}\right)$ of the relationship between log bins of body length and the right-tail of the species-size spectra in the SB and MY.

( $n$, number of size classes to the right of the mode; $r^{2}$, proportion of variance explained by the relation between body size and species frequency; $p$, probability of significant departure from fractal scaling exponents tested using 5000 Monte Carlo simulations. Bias-corrected bootstrap confidence limits $(95 \%)$ based on 5000 bootstrap replications are given in parentheses for all $D_{M}$ and $b_{\text {OLS }}$ values.)

\begin{tabular}{|c|c|c|c|c|c|}
\hline & $D_{M}$ & $n$ & $r^{2}$ & $b_{\mathrm{OLS}}$ & $p$ \\
\hline \multicolumn{6}{|l|}{ SB } \\
\hline autumn & $\begin{array}{c}1.304 \\
(1.252,1.353)\end{array}$ & 18 & 0.997 & $\begin{array}{c}-1.275 \\
(-1.317,-1.234)\end{array}$ & 0.137 \\
\hline winter & $\begin{array}{c}1.490 \\
(1.426,1.551)\end{array}$ & 15 & 0.973 & $\begin{array}{c}-1.372 \\
(-1.519,-1.237)\end{array}$ & 0.083 \\
\hline spring & $\begin{array}{c}1.586 \\
(1.555,1.614)\end{array}$ & 14 & 0.987 & $\begin{array}{c}-1.526 \\
(-1.628,-1.423)\end{array}$ & 0.249 \\
\hline summer & $\begin{array}{c}1.777 \\
(1.730,1.811)\end{array}$ & 13 & 0.983 & $\begin{array}{c}-1.813 \\
(-1.988,-1.653)\end{array}$ & 0.627 \\
\hline \multicolumn{6}{|l|}{ MY } \\
\hline autumn & $\begin{array}{c}1.615 \\
(1.545,1.657)\end{array}$ & 14 & 0.956 & $\begin{array}{c}-1.567 \\
(-1.772,-1.365)\end{array}$ & 0.622 \\
\hline winter & $\begin{array}{c}1.449 \\
(1.386,1.516)\end{array}$ & 17 & 0.965 & $\begin{array}{c}-1.309 \\
(-1.440,-1.183)\end{array}$ & 0.048 \\
\hline spring & $\begin{array}{c}1.578 \\
(1.536,1.615)\end{array}$ & 13 & 0.955 & $\begin{array}{c}-1.626 \\
(-1.842,-1.434)\end{array}$ & 0.677 \\
\hline summer & $\begin{array}{c}1.576 \\
(1.540,1.611)\end{array}$ & 15 & 0.960 & $\begin{array}{c}-1.450 \\
(-1.626,-1.285)\end{array}$ & 0.148 \\
\hline
\end{tabular}

\section{(d) Species-size frequency versus physical habitat structure}

Species-size spectra based on body length showed a significantly unimodal pattern, similar to body mass, in the MY. In the SB, in contrast to the body-mass spectra, body length showed a unimodal distribution in three seasons, while multimodality was recognized in winter (figure 3). When considering the tail distribution of body-size spectra (body size of $\geqslant 1 \mathrm{~mm}$; figure 3 ) to the right of the mode, which coincided with the lower threshold of the pore-particle boundary, the number of species apparently declined logarithmically with increasing body size in both streams (figure 3). The scaling exponents of all seasons in the SB and of autumn, spring and summer in the MY fitted significantly $(p>0.05$; table 3$)$ to the prediction that habitat structures species assemblages of body length more than or equal to $1 \mathrm{~mm}$. An increase in habitat heterogeneity, larger $D_{\mathrm{M}}$, coincides with an increase of intermediate-sized species, while the departure from the model prediction in the winter assemblage in the MY may be related to a seasonal shift towards smaller species (figure 3 ).

\section{DISCUSSION}

The present study demonstrates that the inverse scaling 'law' of the $N-W$ relationship with a symmetric regression $b=-1$ holds across different seasons in two geographically separated stream communities. If energetic considerations alone do not determine the population densities, they may still play a role in determining the maximum densities in communities. In the SB and MY datasets, quantile slopes generally encompassed both the $b=-2 / 3$ and the $b=-3 / 4$ hypotheses, while OLS slope values approached the former. Therefore, metabolic constraints based on a single $b=-3 / 4$ hypothesis, as an explanation for the inverse sca- ling of $N-W$ relationships, must be rejected for invertebrate communities in streams. Notably, none of the upper $90 \%$ and lower $10 \%$ boundary slopes departed significantly from the LAD slope and, consequently, they are not dictated by an underlying species-size distribution, in disagreement with the model predictions of Blackburn et al. (1993). Further, maximum and minimum population densities were larger in small than in medium-sized species, and varied less in small and large species than in intermediate ones. Our data have also indicated that small species have a wider spatial range (i.e. species common to the two streams are smaller (mean \pm s.e. $=86.5 \pm 46.7 \mu \mathrm{g}$ dry mass) than those occurring in only one stream (mean \pm s.e. $=142.7 \pm 59.4 \mu \mathrm{g}$ dry mass) $)$ and greater temporal persistence in a locality.

In contrast to the right-skewed species-size frequency distributions of single-species assemblages (Blackburn \& Gaston 1994), the mass spectra of these stream communities exhibited 'central tendencies'. Significantly, bimodal species mass spectra in the SB contrast with unimodal spectra in the MY. Although a slight, but not significant, tendency towards bimodality was observed, peaks in the species-size spectra of the MY fluctuated seasonally, while those of the SB remained fairly constant. Both stream communities are dominated by meiofaunal species, including both permanent (small amplitude in SB and mode in MY) and temporary (larger amplitude in SB) residents of the stream-bed sediments, while rare species made up the macrofauna of both streams. Central tendencies in size spectra are likely to reflect the phyletic constitution of these stream communities: fewer phyla (and, therefore, species) are included in the smallest and the largest body-size classes, while the intermediate size class encompasses nearly all phyletic groups found in freshwater ecosystems. 
Experiments conducted in the SB showed that small organisms are the first to colonize new habitats, followed by medium to large species (Schmid-Araya 2000), which does not concur with the idea of species invasion around an 'optimum body size' (Blackburn \& Gaston 1994). Small organisms are able to track changes in a fluctuating environment rapidly, becoming abundant in short-lived niches (Stead 2002) in all benthic habitats. Taxa with a wide range of body sizes do not show spatio-temporal persistence and are prone to larger-scale changes in habitat complexity. If body-size differences are the causal basis for differences in resource use, body size could be considered the major factor defining the niche of species (Tokeshi 1999). Once body-size differences have emerged in an ecosystem, they may reinforce differential resource use between species, and contribute to the long-term coexistence of species. These species-size spectra apparently point to ecological and evolutionary processes operating between upper and lower bounds directed by complexity constraints acting, particularly, on larger organisms.

In these stream communities, the number of species (larger than or equal to $1 \mathrm{~mm}$ ) was related to seasonal changes in fractal habitat structure, and higher habitat complexity $\left(D_{M}>1.5\right)$ coincided with increases in the number of intermediate-sized species. By contrast, small species, such as rotifers, have a faster spatiotemporal turnover than larger ones (Schmid-Araya 2000) and may respond to microhabitat changes outside the spatial scale of the current study. Moreover, sediment particle-size distributions display single-fractal and multifractal patterns if smaller particle sizes are included in the analysis (Posadas et al. 2001). These patterns suggest that a wider range of particle-pore sizes might display multifractal scaling, also affecting smaller invertebrate species of the benthic community. It remains to be seen whether similar patterns occur in other benthic habitats and whether investigations on other spatial scales will contribute further to the understanding of scale-related phenomena in ecosystems.

The authors thank the late Gernot Bretschko for his hospitality and invaluable scientific contribution during our studies in the SB, and Erich Lanzenberger for assistance during fieldwork. We also thank two anonymous referees for critically reviewing an earlier draft of the manuscript. This work was funded by NERC grant GR3/09844 to M.T., and the Austrian FWF research grant $8007-\mathrm{BIO}$ to P.E.S.

\section{REFERENCES}

Babu, G. J. \& Feigelson, E. D. 1992 Analytical and Monte Carlo comparisons of six different linear least squares fits. Commun. Statist. Simul. Comput. 21, 533-549.

Blackburn, T. M. \& Gaston, K. J. 1994 Animal body size distributions: patterns, mechanisms and implications. Trends Ecol. Evol. 9, 471-474.

Blackburn, T. M., Lawton, J. H. \& Pimm, S. L. 1993 Nonmetabolic explanations for the relationship between body size and animal abundance. F. Anim. Ecol. 62, 694-702.

Bretschko, G. \& Klemens, W. E. 1986 Quantitative methods and aspects in the study of the interstitial fauna of running waters. Stygologia 2, 297-316.

Brown, J. H. 1995 Macroecology. University of Chicago Press. Cyr, H. 2000 Individual energy use and the allometry of population density. In Scaling in biology (ed. J. H. Brown \& G. B. West), pp. 267-295. Oxford University Press.
Damuth, J. 1987 Interspecific allometry of population density in mammals and other animals: the independence of body mass and population energy-use. Biol. f. Linn. Soc. 31, 193-246.

Draper, N. R. \& Smith, H. 1998 Applied regression analysis. New York: John Wiley \& Sons.

Efron, B. \& Tibshirani, R. J. 1993 An introduction to the bootstrap. New York: Chapman \& Hall.

Harvey, P. H. \& Pagel, M. D. 1991 The comparative method in evolutionary biology. Oxford University Press.

Isobe, T., Feigelson, E. D., Akritas, M. G. \& Babu, G. J. 1990 Linear regression in astronomy. Astrophysical f. 364, 104113.

Kampichler, C. 1999 Fractal concepts in studies of soil fauna. Geoderma 88, 283-300.

Lawton, J. H. 1986 Surface availability and insect community structure: the effects of architecture and fractal dimension of plants. In Insects and the plant surface (ed. B. E. Juniper \& T. R. E. Southwood), pp. 317-331. London: Edward Arnold.

Mandelbrot, B. 1983 The fractal geometry of nature. San Francisco: Freeman and Co.

Marquet, P. A. 2000 Invariants, scaling laws, and ecological complexity. Science 289, 1487-1488.

Marquet, P. A., Navarrete, S. A. \& Castilla, J. C. 1990 Scaling population density to body size in rocky intertidal communities. Science 250, 1125-1127.

May, R. M. 1986 The search for patterns in the balance of nature: advances and retreats. Ecology 67, 1115-1126.

Morse, D. R., Lawton, J. H., Dodson, M. M. \& Williamson, M. H. 1985 Fractal dimension of vegetation and the distribution of arthropod body lengths. Nature 314, 731-732.

Peters, R. H. 1983 The ecological implication of body size. Cambridge Studies in Ecology. Cambridge University Press.

Posadas, A. N. D., Gimenez, D., Bitelli, M., Vaz, C. M. P. \& Flury, M. 2001 Multifractal characterization of soil particlesize distributions. Soil Sci. Soc. Am. F. 65, 1361-1367.

Scharf, F. S., Juanes, F. \& Sutherland, M. 1998 Inferring ecological relationships from the edges of scatter diagrams: comparison of regression techniques. Ecology 79, 448-460.

Schmid, P. E. 1993 Random patch dynamics of larval Chironomidae (Diptera) in the bed sediments of a gravel stream. Freshwat. Biol. 30, 239-255.

Schmid, P. E. 2000 The fractal properties of habitat and patch structure in benthic ecosystems. Adv. Ecol. Res. 30, 339-401.

Schmid, P. E., Tokeshi, M. \& Schmid-Araya, J. M. 2000 Relation between population density and body size in stream communities. Science 289, 1557-1560.

Schmid-Araya, J. M. 1994 Temporal and spatial distribution of benthic microfauna in sediments of a gravel streambed. Limnol. Oceanogr. 39, 1813-1821.

Schmid-Araya, J. M. 2000 Invertebrate recolonization patterns in the hyporheic zone of a gravel stream. Limnol. Oceanogr. 45, 1000-1005.

StataCorp 1999 STATA statistical software: release 6.0. College Station, TX: Stata Corporation.

Stead, T. 2002 Body-size distribution in stream communities. $\mathrm{PhD}$ dissertation. University of London.

Tokeshi, M. 1999 Species coexistence. Ecological and evolutionary perspectives. Oxford: Blackwell Science.

West, G., Brown, J. H. \& Enquist, B. J. 1999 The fourth dimension of life: fractal geometry and allometric scaling of organisms. Science 284, 1677-1679.

As this paper exceeds the maximum length normally permitted, the authors have agreed to contribute to production costs.

Visit http://www.pubs.royalsoc.ac.uk to see an electronic appendix to this paper. 